\title{
钯催化卡宾迁移插入合成烯基硼酸酯
}

\author{
王自坤王 亚毕锡和* \\ (东北师范大学化学学院 长春 130024)
}

\section{Synthesis of Alkenylboronates via Pd-Catalyzed Carbene Migration Insertion}

\author{
Wang, Zikun Wang, Ya Bi, Xihe* \\ (Department of Chemistry, Northeast Normal University, Changchun 130024)
}

烯基硼酸酯是一种重要的有机合成子, 广泛应用于 制备高附加值烯基化合物 ${ }^{[1]}$ 和多官能化烷基硼酸酯 ${ }^{[2]}$. 因此, 发展烯基硼酸酯的新合成方法学一直备受化学家 关注. 烯基卤化物及其类似物的交叉偶联 ${ }^{[3]}$ 或锂卤交 换一硼化反应是制备烯基硼酸酯的一种常见方法. 但是 由于烯基卤化物及其类似物相对昂贵且制备繁琐，在一 定程度上限制了此方法的普遍使用. 炔烃的嗍氢化及碳 硼化反应是另一种常用的烯基硼酸酯的制备方法. 然 而, 端炔的硼氢化反应大多只能制备 1,2-二取代烯基硼 酸酯, 极少能够合成 1,1-二取代烯基硼酸酯 [4]; 而非对 称内炔的嗍氢化或碳硼化反应, 因缺乏区域选择性而缺 乏实用价值 ${ }^{[5]}$. 因此, 发展高效、高选择性烯基硼酸酯的 制备方法仍然高度需要.

北京大学化学与分子工程学院王剑波课题组 ${ }^{[6] 一-~}$ 致力于金属卡宾参与的交叉偶联反应研究, 并取得了突 破性研究进展. 最近, 他们课题组利用对甲基苯磺酰腙 与联嗍化合物的氧化交叉偶联反应, 成功地为烯基硼酸 酯的制备提供了一种简单、实用的方法(Scheme 1), 此 方法具有原料廉价易得、底物范围宽泛、反应高效以及 高立体选择性等优点. 此外, 他们和北京化工大学雷鸣 课题组合作, 应用密度泛函理论(DFT)计算对该反应的 机理进行了深入探讨 ${ }^{[7]}$.

首先, 作者研究了各种因素对反应的影响, 包括: 氧化剂、催化剂、配体、碱、溶剂及温度. 经过条件篮 选, 最终确定以 2,5-二甲基对苯醌作为氧化剂、氢化钠 作为碱、醋酸钯作为催化剂、三间基苯基膦作为配体、 甲苯作为溶剂、在 $90{ }^{\circ} \mathrm{C}$ 的条件下可获得最高收率的烯 基硼酸酯.

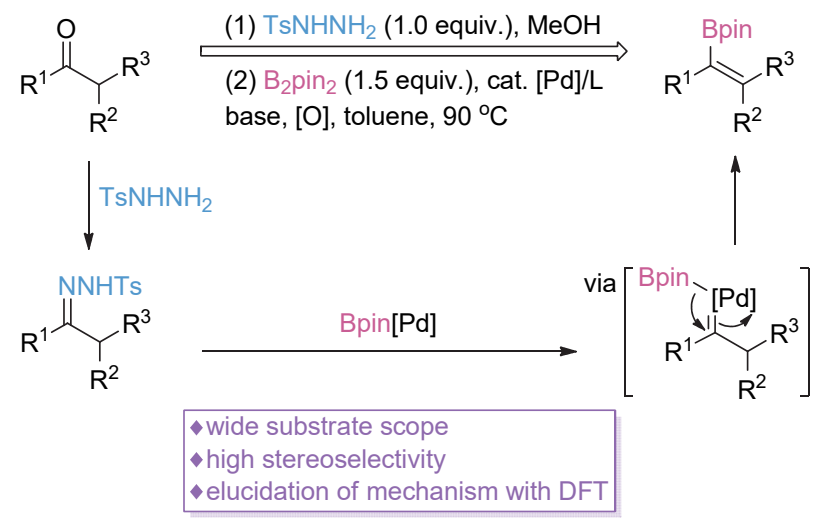

图式 1 通过钯硼物种构建烯基硼酸酯

Scheme 1 Alkenylboronates constructed from boron-Pd species

接着，作者对反应的底物适用范围进行了考察，发 现该反应具有良好的底物普适性(Scheme 2). 在该交叉 偶联反应中, 通过对反应条件的简单调控, 分别以中等 到高收率得到相应的二取代、三取代以及四取代的烯基 硼酸酯. 同时, 该反应对于官能团具有很好的兼容性, 诸如氯、溴、硼酸、酯、醚、胺及硅梄等官能团对该反 应均无明显影响. 并且, 该反应具有较高的立体选择性, 可以得到以 $E$ 式为主的三取代烯基硼酸酯. 值得注意的 是, 作者还把此方法与传统的 Miyaura 硼化反应进行了 实验对比, 结果显示, 通过此反应制备烯基硼酸酯具有 更高的收率和更好的立体选择性.

为了清晰阐释该反应的机理及其立体选择性的起 源, 作者对此反应进行了 DFT 计算研究. 计算结果表 明, 反应主要经历了六个基本步骤(Scheme 3A): 卡宾 形成、嗍迁移插入、 $\beta$-氢消除、还原消除、氧化加成和 转金属化，其中，在 $\beta$-氢消除反应过程中，电子效应是

* Corresponding author. E-mail: bixh507@nenu.edu.cn. Published online August 19, 2021. 


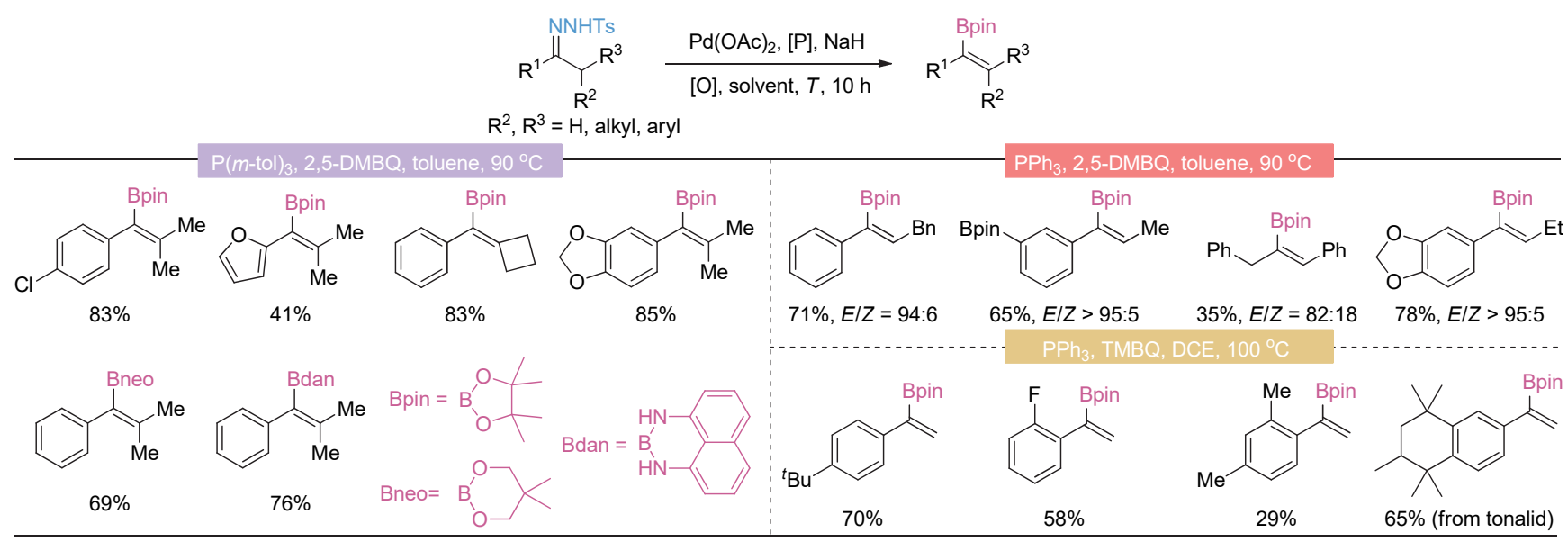

图式 2 烯基硼酸酯反应底物范围研究

Scheme 2 Research scope of alkenyl borate reaction substrate

(A) Proposed reaction mechanism

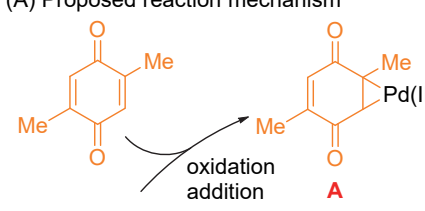

$\int_{\mathrm{NaH}^{\text {reductive }}}^{\mathrm{Pd}(0) \mathrm{L}_{n}}$

$\mathrm{L}_{n} \mathrm{Pd}_{\backslash_{Y}^{\prime}}^{\prime \mathrm{H}}$

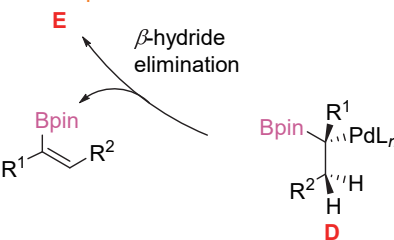

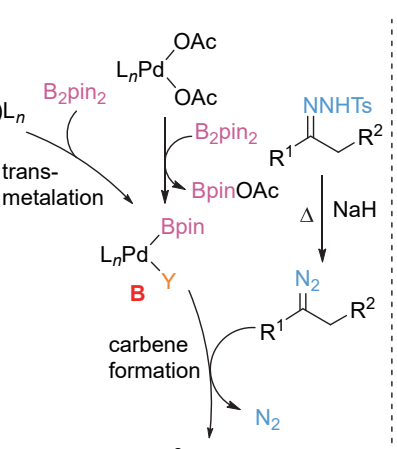

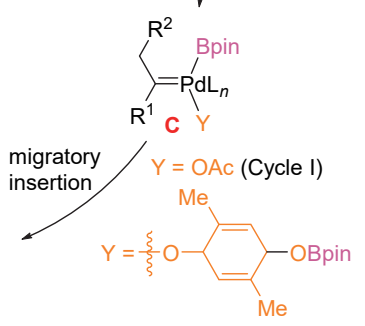

(B) Free energy profiles for the $\beta$-hydride elimination step catalyzed by palladium

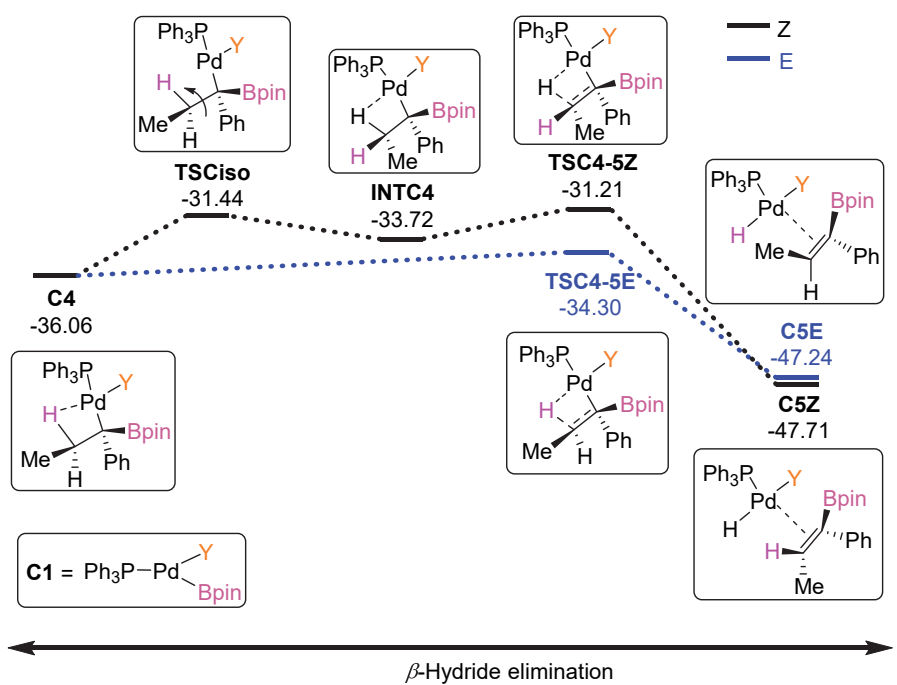

图式 3 反应机理研究

Scheme 3 Study on the reaction mechanism

致使产物以 $E$ 式为主的重要原因(Scheme 3B).

综上所述，该论文报道了一种钯催化的对甲基苯磺 酰腙与联硼化合物的氧化交叉偶联反应，为烯基硓酸酯 的制备提供了一种简单、实用的新方法. 该方法具有原 料廉价易得、底物范围宽泛、反应高效及高立体选择性 等优点, 极大地改进了烯基硼酸酯类化合物的制备工 艺, 对于有机嗍化学的发展具有重要推动作用.

\section{References}

[1] Suzuki, A. Angew. Chem., Int. Ed. 2011, 50, 6722.

[2] Bera, S.; Mao, R.; Hu, X. Nat. Chem. 2021, 13, 270.

[3] Takagi, J.; Takahashi, K.; Ishiyama, T.; Miyaura, N. J. Am. Chem. Soc. 2002, 124, 8001.

[4] Ojha, D. P.; Prabhu, K. R. Org. Lett. 2016, 18, 432.

[5] Itoh, T.; Shimizu, Y.; Kanai, M. J. Am. Chem. Soc. 2016, 138, 7528.

[6] Xia, Y.; Qiu, D.; Wang, J. Chem. Rev. 2017, 117, 13810.

[7] Ping, Y.; Wang, R.; Wang, Q.; Chang, T.; Huo, J.; Lei, M.; Wang, J. J. Am. Chem. Soc. 2021, 143, 9769. 